\title{
Chemical studies of Chinese coinage II: from Qin to Yuan (221 BCE-1368 CE)
}

\author{
A. M. Pollard ${ }^{2}$ and Ruiliang Liu ${ }^{1,2^{*}}$
}

\begin{abstract}
This paper surveys of the chemical composition of the copper alloy coinage in China from the Qin Dynasty to the end of the Yuan Dynasty (221 BCE-1368 CE). It shows a dramatic change in the alloying practice used to cast these coins from the Qin unification (after 221 BCE), compared to that practiced in the pre-Qin. There are a number of shifts in the quality of the coinage from dynasty to dynasty, such as the obvious debasement of the Southern Song coinage (1127-1279 CE) when compared to that of the previous Northern Song dynasty (960-1127 CE). Particular attention is paid to the low levels of zinc in the coinage over the period. Although not as obvious as the switch to brass coinage in the Ming, certain periods do show occasional values of zinc up to $2-4 \%$, which we suggest could reflect the sporadic input of recycled brass (Cu-Zn alloy) into the raw material melt. There were several major suppressions of Buddhism during this period, when Buddhist brass statuary was recycled into the coinage, providing a plausible mechanism for the injection of small quantities of zinc into the coinage alloy. A diachronic study of the amounts of iron in the metal, taken to indicate changes to the manufacturing process of copper, also show changes over time. The median levels of iron jump from the Qin (221-206 BCE) to the Western Han (206 BCE-9 CE), possibly reflecting the adoption of slagging processes in the production of the copper, followed by a gradual decline to the Northern Song (960-1127 CE), and a rapid increase during the Southern Song (1127-1279 CE). Finally, a study of changes in the content of silver over time reveals differences in the sources of lead, or changes in lead and silver extraction technologies, over the period.
\end{abstract}

Keywords: Chinese coins, Copper alloy, Brass, Buddhism

In a previous paper [1], we have considered the published chemical compositions of the Pre-Qin (before 221 BCE) copper alloy coinage of China. These coins were cast in a wide range of distinctive shapes, and the aim of that paper was to investigate the alloying practices involved in making the metal from which they were cast. It had previously been assumed that these coins were made to a 'target alloy composition', by separately adding variable amounts of lead and tin to copper, and most summaries of these data have been presented in terms of average compositions for a particular coin type. However, the chemistry of most coin types is highly variable, and, by

\footnotetext{
*Correspondence: ruiliang.liu@arch.ox.ac.uk

${ }^{2}$ Research Laboratory for Archaeology and the History of Art, School

of Archaeology, University of Oxford, Oxford, England

Full list of author information is available at the end of the article
}

a combination of modelling and the use of trend lines in the plotted $\mathrm{Cu}-\mathrm{Sn}-\mathrm{Pb}$ data, we showed that most of them appear to have been made by mixing together two starting materials-one containing copper, lead and tin (in proportions similar to the composition of the bronze used to cast contemporary ritual vessels), and one containing only copper and lead. This was unexpected, and therefore the current paper extends this study into the later period, covering the Qin to Yuan Dynasties. The aim here is to compare alloying practices in coin manufacture across this time period, and with that practiced in the PreQin period. It is freely acknowledged that the approach taken is at a high level, with a consequent coarse resolution, both chronologically and geographically. It is no substitute for a detailed numismatic study, and it is certainly possible that a more refined analysis, particularly in terms of breaking the data down to individual mints

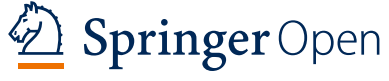

(c) The Author(s) 2021. This article is licensed under a Creative Commons Attribution 4.0 International License, which permits use, sharing adaptation, distribution and reproduction in any medium or format, as long as you give appropriate credit to the original author(s) and the source, provide a link to the Creative Commons licence, and indicate if changes were made. The images or other third party material in this article are included in the article's Creative Commons licence, unless indicated otherwise in a credit line to the material. If material is not included in the article's Creative Commons licence and your intended use is not permitted by statutory regulation or exceeds the permitted use, you will need to obtain permission directly from the copyright holder. To view a copy of this licence, visit http://creativeco mmons.org/licenses/by/4.0/. The Creative Commons Public Domain Dedication waiver (http://creativecommons.org/publicdomain/ zero/1.0/) applies to the data made available in this article, unless otherwise stated in a credit line to the data. 
where that is possible, would reveal additional detail or exceptions to the generalities discussed here. Nevertheless, we feel that there is some considerable value in using the chemical analysis of the coinage to carry out a diachronic study of alloying.

The coinage of the Ming and Qing dynasties is not considered here, for several reasons. One is that the alloying practice changes dramatically to include high levels of zinc after Jiajing [2], and also it becomes increasingly possible during the Qing to resolve the date of the coinage to a single year. Another factor is that the use of silver as a medium of exchange increases strongly during the Ming and Qing [3]. The alloying of copper coinage during the Ming and Qing will be considered separately in a future paper.

\section{Brief history of Chinese coinage from the Qin to the Yuan dynasties (221 BCE-1368 CE)}

The Chinese literature on Chinese coinage is extremely extensive, including the works of Zhou Weirong, Dai Zhiqiang and many others. Wang [4] gives an overview of the early European language literature on Chinese numismatics, including a short introduction to key earlier works in Chinese. More recent information can be found in a few other references [5] [6, 7], as well as journals such as Zhongguo Qianbi (China Numismatics). A standard introduction to the cast copper-based coinage of China in English is the work of Hartill [8].

Table 1 gives the approximate dates of the various dynasties between Qin unification in $221 \mathrm{BCE}$ to the end of the Yuan (Mongol) Dynasty (1368 CE). When Qin Shi Huang Di united China the dominant small currency gradually became the circular copper coin with a square central hole, known as Ban Liang (牛两), replacing the earlier coinage in the shape of knives and spades, but still manufactured by casting rather than striking. The Ban Liang coin typically weighed around $8 \mathrm{~g}$, although the weight was reduced over time (Hartill, 2005, 83). Soon after the start of the succeeding Western Han Dynasty (206 BCE-9 CE), private mints were allowed to cast small "elm seed" coins (Yu Jia 榆英) alongside the official Ban Liang coinage. In 119 BCE, the Ban Liang was replaced by the San Zhu (三铢, of weight approximately $2 \mathrm{~g}$ ), and from $118 \mathrm{BCE}$, the Wu Zhu (五铢weighing around 3.25 g: Hartill $(2005,85))$. The usurper Wang Mang, who founded the Xin dynasty (9-23 CE), reformed the currency, re-introducing spade and knife coins. Towards the end of his reign, he introduced the Huo Quan (货 泉), a coin of similar form to the Ban Liang but usually weighing around $3 \mathrm{~g}$, to replace the Western Han Wu Zhu coinage (Hartill 2005, 86). The Huo Quan continued in circulation into the restored Eastern Han Dynasty (c. 23-220 CE), but Wu Zhu coins continued as the main copper coinage until the end of the sixth century $\mathrm{CE}$ (Fig. 1).

The Eastern Han was followed by the Three Kingdoms (Wei, Shu and Wu: 220-280 CE), with a short period of unification in the south under the Jin Dynasty (266-420 $\mathrm{CE})$, and the Sixteen Kingdoms in the north. This was followed by a further period of significant fragmentation known as the Northern and Southern Dynasties (386-589 CE. Unification was again achieved under the Sui Dynasty (581-618 CE). Wu Zhu coins continued to be issued during these periods, often minted by the separate states. The Sui also used Wu Zhu coins, minted at different places. After $605 \mathrm{CE}$, private mints were also established, resulting in a deterioration of the coinage. The Tang Dynasty (618-907 CE) introduced the Kai Yuan Tong Bao (开元通宝) in $621 \mathrm{CE}$, which became the standard coinage for the next 300 years. The weight was about $1.5 \mathrm{~g}$. Both copper extraction and coin minting were state controlled, with private minting punishable by death or various other penalties [8]. For the first time that we know of, the composition of coinage alloy was recorded, in this case as $83 \%$ copper, $15 \%$ lead and $2 \%$ tin. This composition derives from the ancient document New Book of Tang (新唐书, written in the Song dynasty). In the Section of Shihuozhi (食货志, Record of Goods), it notes that every furnace in each cast/pouring produced 3,300 strings of coins (ca. 3,300,000 coins), from 21,200 jin of copper, 3,700 jin lead and 500 jin tin (1 jin (catty) is approximately $600 \mathrm{~g}$ ), employing 30 craftspeople. This recipe gives the composition quoted, assuming no losses. The reference is also confirmed by another record from chapter nine of Tongdian (通典, written in the Tang dynasty), which says every cast (of coins) used approximately 21,210 jin of copper, 3709 jin of white lead, and 540 jin of black. However, successive Tang Emperors had to constantly reaffirm the regulations by releasing new policies or punishments, and exchange those forgeries circulating in the market with either goods (e.g., crops, textile) or genuine coins. Following the establishment of a commissioner for coin casting in $737 \mathrm{CE}$, ten mints were recorded in $739 \mathrm{CE}$, with a total of 89 furnaces producing 327,000 strings of cash a year (See New Book of Tang: Section Shihuozhi; also Hartill $(2005,103))$. Cash is the term used for all types of Chinese round coinage with a square central hole, and a string was nominally 1000 cash (about $1.5 \mathrm{~kg}$ of metal). From the late $740 \mathrm{~s}$, the previously-employed conscripted workers were replaced by skilled artisans for coin casting [8]. However, shortage of copper over the next century (evidenced by restrictions on how much cash could be held by each household [9], resulted, by $834 \mathrm{CE}$, in the output of official mints falling to 100,000 strings of cash a year. 


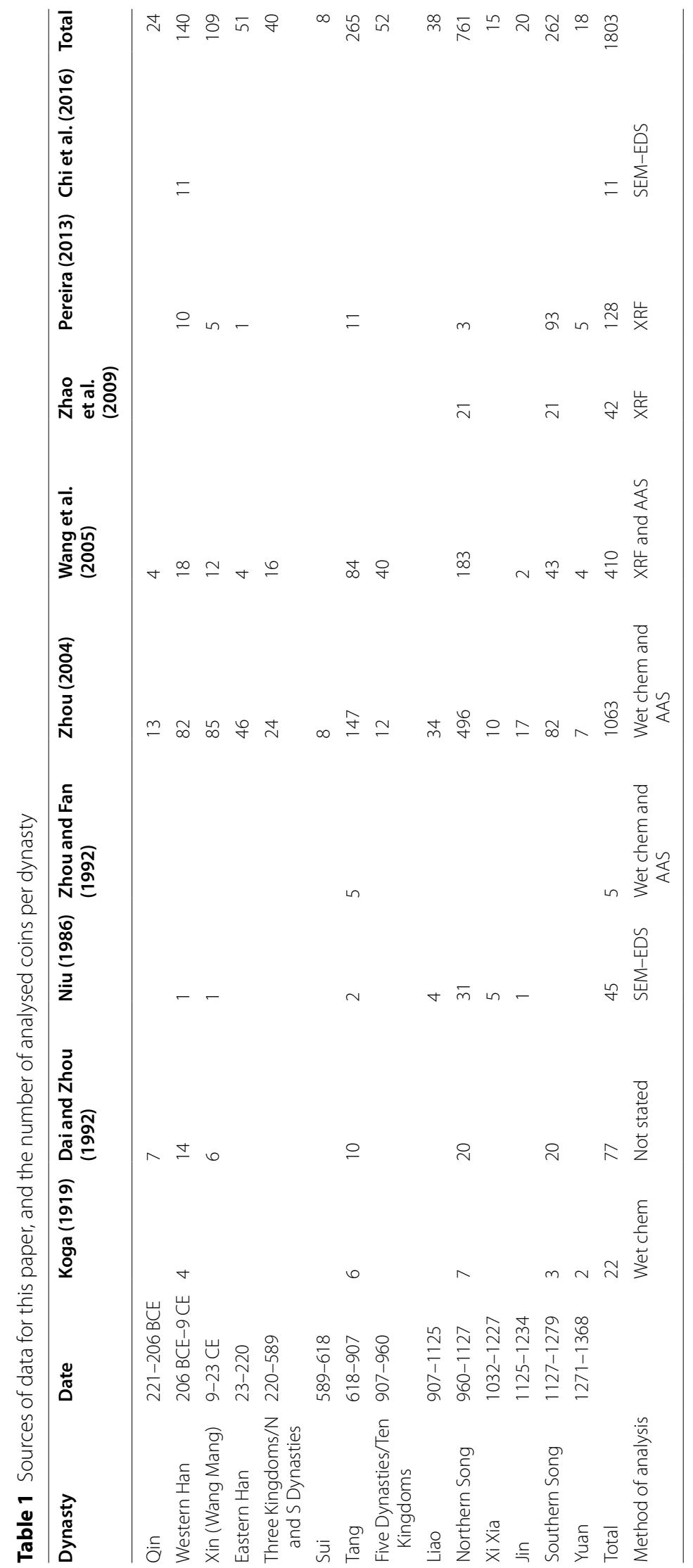



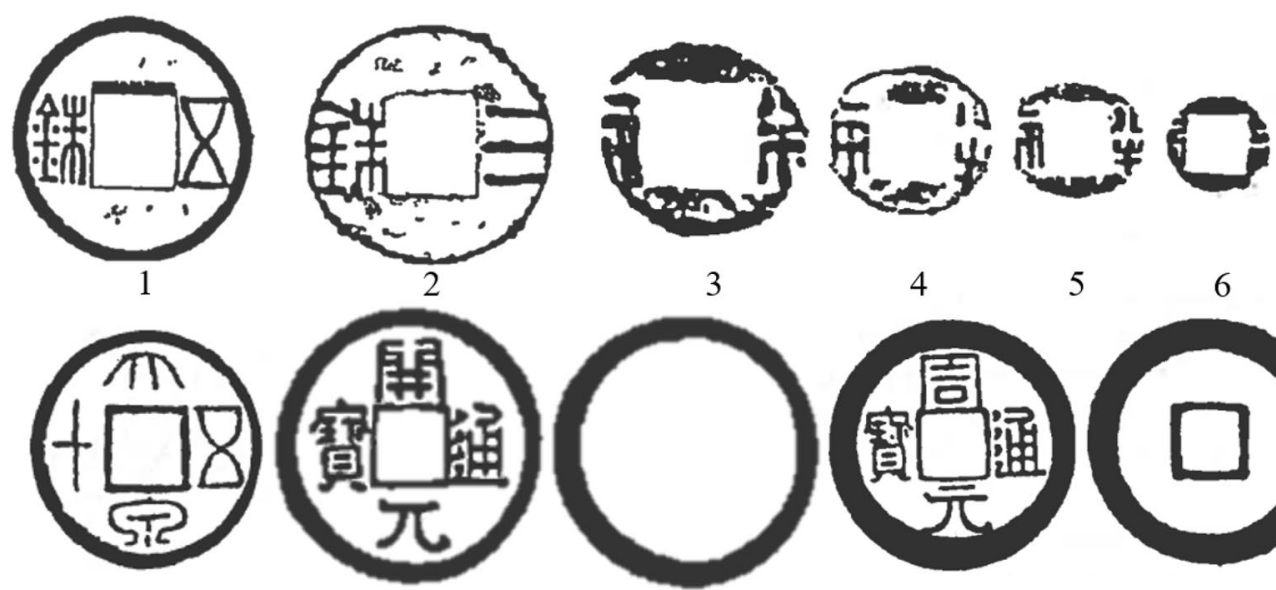

$5 \quad 6$

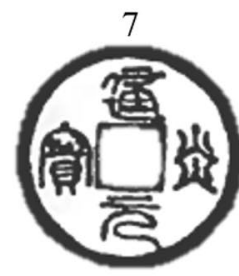

12
8

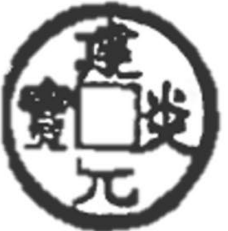

13

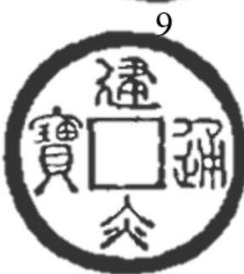

14
10

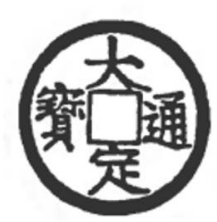

15

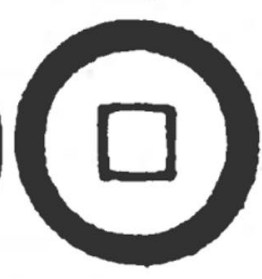

11

Fig. 1 Some coins mentioned in the text (1 Han dynasty Wu Zhu, 2 Han dynasty San Zhu, 3-6 Han dynasty Yu Jia, 7 Wang Mang Da Quan Wu Shi, 8-9 Tang dynasty Kai Yuan Tong Bao, 10-11 Later Zhou dynasty Zhou Yuan Tong Bao, 12-13 Song dynasty Jian Yuan Tong Bao (front and back), 14 Song dynasty Jian Yan Tong Bao (front and back), 15 Jin dynasty Da Ding Tong Bao, 16 Yuan dynasty Tian Qi Tong Bao, modified from Hartill, 2005)

During the Great Anti-Buddhist persecution of the Tang Emperor Wu Zong (842-845 CE), a great many Buddhist monasteries and temples $(46,600)$ were destroyed and their property confiscated [9]. Monasteries and nunneries had previously been tax exempt, and, under the edict of $845 \mathrm{CE}$, monks and nuns were required to hand over their wealth to the government unless they returned to lay life and paid taxes. The confiscated copper bells, gongs, incense burners and statues were used to cast coins in local mints under the control of the provincial governors. When he ascended the Throne in $847 \mathrm{CE}$, the succeeding Emperor, Xuānzong, as part of his purge of the Court, revoked the edict, and it is said that the new coins were recast to make replacement Buddhist statues.

The fall of the Tang in 907 CE was followed by a period of disunity, known in northern China as the Five Dynasties, which were short-lived but ruled consecutively, and in the south as the Ten Kingdoms, which were overlapping. During the Later Zhou (951-960 CE) of the Five Dynasties, in $955 \mathrm{CE}$, once again a shortage of copper restricted the supply of coins, so the Emperor Shi Zong prohibited households from holding bronze utensils [8], and again used re-melted Buddhist bronze statues from 3356 Temples to make coins. These coins (Zhou Yuan Tong Bao, 周元通宝) were believed to have spiritual powers inherited from the Buddhist statues, and were subsequently much-copied [10]. In the south, cast iron and cast lead coins appeared during the Ten Kingdoms.

At the end of the Five Dynasties, in 960, mutiny ended the reign of the Later Zhou, and established the Northern Song Dynasty (960-1127 CE), which again unified China and her currency. In 1019, the composition of coinage alloy was reported as being copper $64 \%$, lead $27 \%$ and tin 9\% (see Wenxian Tongkao, Chapter nine, Coin II, written in the Yuan dynasty). This currency was established using the output of new copper mines, and by the Yuanfeng period (元丰, 1078-1085 CE) of the Emperor Shenzong, over five million strings of bronze coins a year were produced by 17 different mints (Hartill 2005, 125). The Southern Song dynasty (1127 -1279) was established when the Northern Song capital at Kaifeng was taken by the Jurchen Jin dynasty in 1127 and the Song government fled south to Hangzhou. The Southern Song coinage was lower in quality compared to the coins of the Northern Song dynasty because of the lack of available copper sources, and minting was frequently interrupted. For example, copper utensils were confiscated in 1136, and the standard of coinage was reduced to a copper content of $54 \%$, with c. $5 \%$ tin and the balance lead [8]. From 1180 onwards, coins began to carry a number corresponding to the year of minting. 
The Liao dynasty created by the Khitans in Northern China and adjacent regions of Mongolia, North Korea, and the Russian Far East from 907 until 1125 when most of their territory was conquered by the Jurchens who established the Jin dynasty (1125-1234 CE). Liao coins are similar in appearance to the cash of the Song dynasty but with different inscriptions, and are said to have been made of 'red copper' [8]. The Jin dynasty used paper money, but began to produce cash coins in 1158, replacing the coins of the Liao and Song dynasties. An edict was issued in 1161 to ban the melting down of coins to make utensils, and new copper mines were sought to increase the copper supply [8].

The Tangut Xi Xia Empire extended over northwestern China from 1032 until $1227 \mathrm{CE}$, when it was destroyed by the Mongols. The coinage of Xi Xia was superior in casting quality compared to that of the Liao dynasty, but was only produced in any quantity between 1149 and 1193 CE [8]. The Mongol conquest of China began when Genghis Khan attacked the Xi Xia in 1209, and in 1271 Kubilai Khan declared the Yuan dynasty as the name of the Mongol khanate that ruled over all of China from 1271 to 1368 . The Southern Song Dynasty finally surrendered in 1279. The Mongols allowed for the continuation of locally minted copper currency, as well as permitting the continued use of previously created and older forms of currency. Paper money, first used in the Tang, became common currency during the Song dynasties and the Yuan, often to cover for times when copper was in short supply.

\section{Chemical analyses of Chinese coins}

The sources of data on the chemical analyses and the methods of analysis of Chinese copper alloy coins have been discussed in Pollard and Liu [1]. Briefly, Table S1 in that publication gives a list of 40 publications which contain analyses of Chinese copper-based copper coinage of all periods, and which are transcribed into the database ('Chinese Coins') available at http://flame.arch.ox.ac.uk/ public-resources/. Further publications have been identified since then and added to this database, giving a total of 44 publications and 5278 analyses, although the total number of individual coins represented is less than that because a number of compilations republish previous data. Much of the earlier published data mainly focus only on the copper, lead and tin contents. The most comprehensive single data source is Zhou [7], which reports 1250 new analyses, plus a further c. 700 from 20 other publications. In western scholarship, the largest contribution is that of the British Museum [5], which collects c. 700 analyses from earlier British Museum publications [11-13] and adds more illustrations and commentary. Many of the publications listed in Table S1 of reference
[1] have been reproduced in a summary volume [6], which republishes 28 papers in Chinese and 12 in English.

It is important to consider the validity of carrying out a meta-analysis of chemical data from a number of sources, and in particular from different types of instrument. This issue has been much-debated in the archaeological literature [14]. Undoubtedly, analytical quality (in terms of detection levels, precision, accuracy) vary dramatically over time, and are rarely reported in sufficient detail for careful analysis. Probably more significant in the case of archaeological metals, the degree to which the corrosion layer is removed before analysis is a critical factor. For the data analysis carried out here, involving primarily measurements of the major coinage elements copper, lead and tin, in a large number of coins, it is highly unlikely that either systematic bias or erratic individual analyses would significantly affect the overall main conclusions about alloying practices. It is, however, much less certain that minor and trace element measurements (in this case, zinc, silver and iron) are equally robust, and those discussions need to be taken with more caution.

\section{Alloying of post-Qin coinage}

Table 1 lists the publications (from Table S1 in reference [1], with two additions) which have been used to provide data for this paper, and the total number of coins included from each dynastic period. At a minimum, each analysis reports copper, tin and lead, and many include iron and zinc, but the trace elements are relatively infrequent. The entire database contains 1803 analyses, but the dynastic coverage is very uneven-the short-lived Sui dynasty (589-618 CE) is represented here by only eight coins, whereas the Northern Song (960-1127 CE) has 761 analyses. Also listed is the analytical technique(s) used in each publication, where it is stated.

In a previous publication [1] we reported the rather unexpected observation that the alloying composition of most of the pre-Qin coinage (before 221 BCE) can be explained by a binary 'recipe' of mixing a copper-tinlead alloy with a 'diluent' of copper-lead alloy, rather than being a simple mixture of three independent components $(\mathrm{Cu}, \mathrm{Pb}$ and $\mathrm{Sn})$. This result was obtained by comparing the composition of a large number of pre-Qin coins (c. 500 analyses) with a number of modelled compositional series, and noting that the overall shape of the distribution could plausibly be explained by a simple dilution formula. Figure $2 \mathrm{a}$ shows a plot of $\mathrm{Cu}$ vs. $\mathrm{Sn}$ for all the pre-Qin coinage, upon which is superimposed two model mixing lines, one for a starting alloy of $80 \% \mathrm{Cu}, 15 \% \mathrm{Sn}$ and $5 \% \mathrm{~Pb}$ diluted with increasing quantities of a 50/50 mixture of $\mathrm{Cu}$ and $\mathrm{Pb}$, and the second a mixing line for the same starting alloy with the addition of pure $\mathrm{Pb}$ alone. Although by no means a perfect fit, the implication 


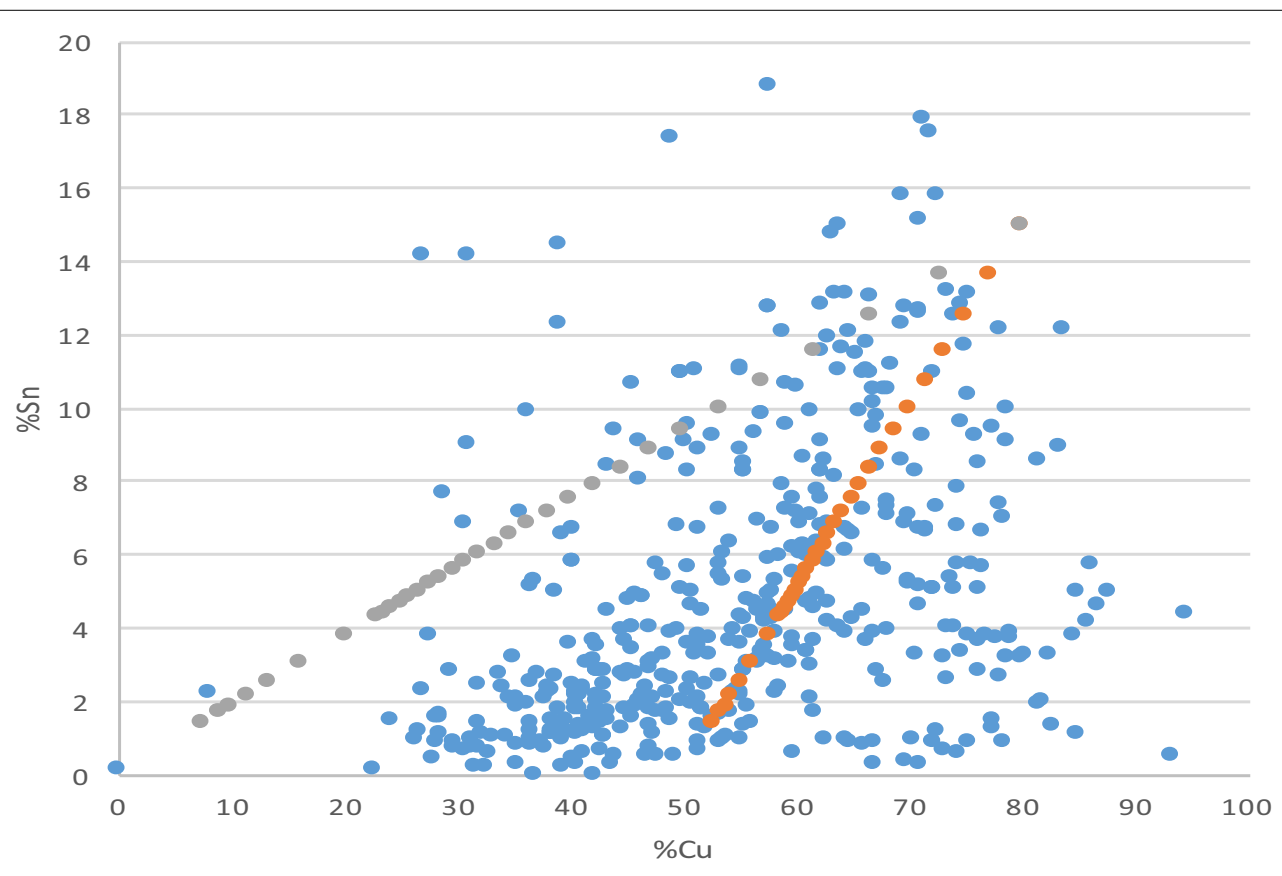

- coin data model 50/50 Cu/Pb model pure Pb

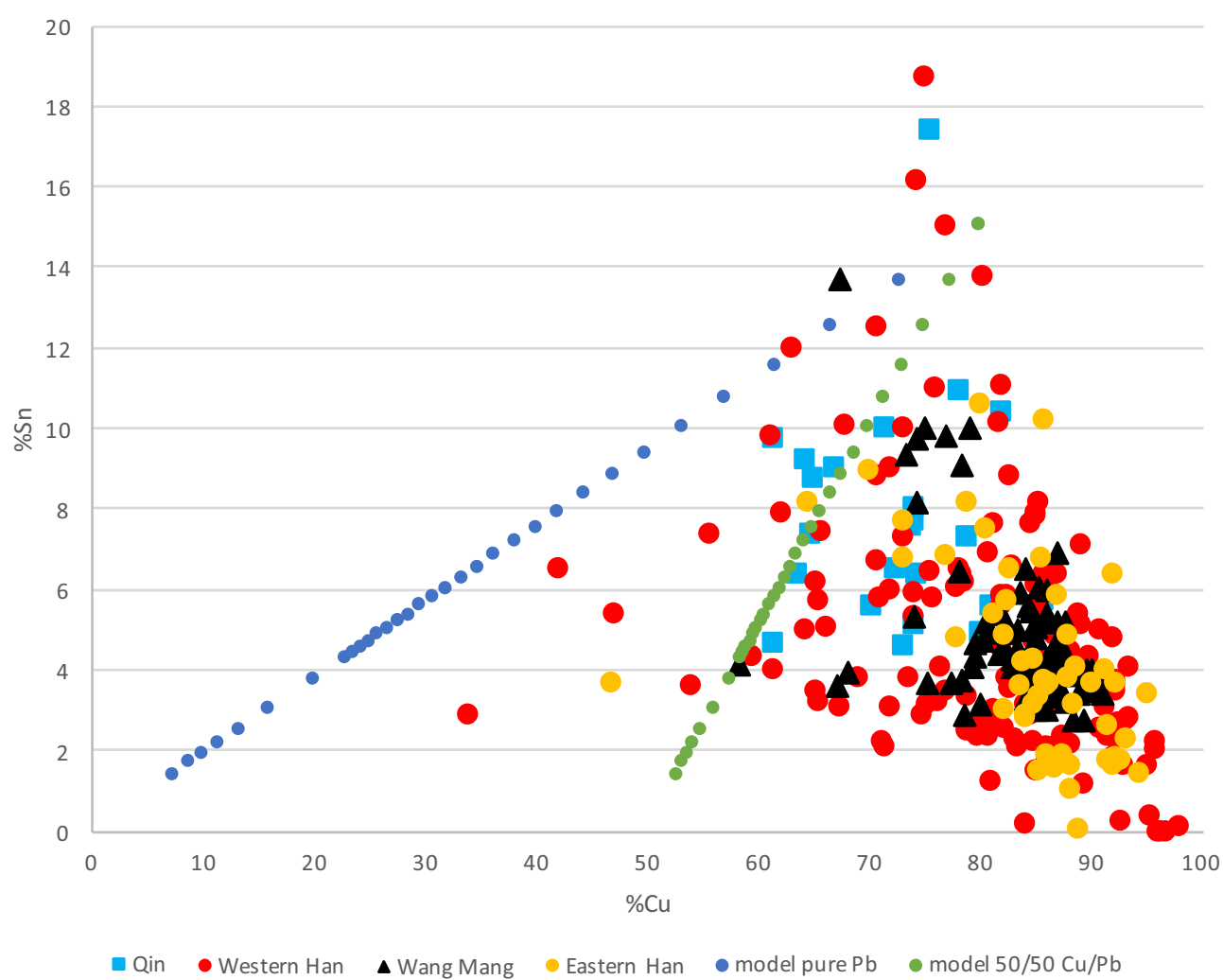

Fig. 2 Plot of \%Cu vs. \%Sn in a pre-Qin coinage, with two model mixing lines (bronze plus 50/50 Cu/Pb and bronze plus pure lead) ([1]; b coinage of Qin to Eastern Han dynasties (221 BCE-220 CE: data sources as in Table 1) 
is that a 'recipe' similar to the bronze plus $50 / 50 \mathrm{Cu} / \mathrm{Pb}$ model gives a plausible explanation for the observed data.

The same plot for Qin to Eastern Han coinage (221 BCE-220 CE) shows a markedly different correlation (Fig. 2b), which suggests that this binary pre-Qin 'recipe' was replaced after the Qin unification. In this case, the data appear to radiate from an approximately pure copper composition, with a variable proportion of tin added up to a maximum of $20 \%$. When combined with Fig. 3 (a plot of \% Cu vs \% Pb for the same Qin to Eastern Han data, showing a strong negative correlation), the 'recipe' for producing these coins appears to be a starting-point of approximately pure copper and a primary dilution with lead, exceptionally up to $50 \%$, with some variable additions of tin (from zero up to 20\%). This recipe was probably achieved with three independent starting components corresponding to relatively pure copper, lead and tin. As shown in Fig. 4, there is no strong relationship between $\% \mathrm{~Pb}$ and $\% \mathrm{Sn}$ in these coins, which suggests that these two components were added independently, thus corresponding intuitively with what might be expected for making leaded bronze coinage.
There appears to have been a major change in the alloying practice of copper coinage from the Qin Dynasty onwards, possibly corresponding to the introduction of Ban Liang coinage by Qin Shi Huang Di. Although the data on the chemistry of Qin coinage are currently too few (24 published analyses) to make a reliable judgement, Fig. $2 \mathrm{~b}$ suggests that this transition occurred during the Qin dynasty, since some Qin compositions could conform to the earlier 'recipe', but some seem to adhere to the later practice. There are also significant differences from dynasty to dynasty, particularly during the short Xin (Wang Mang) dynasty (9-23 CE) between the Western and Eastern Han. Figure 5 shows a plot of $\mathrm{Pb} / \mathrm{Cu}$ vs $\mathrm{Sn} / \mathrm{Cu}$ for Qin, Western Han, Wang Mang and Eastern Han. The use of this form of presentation was first proposed by Caley [15] in his study of Greek bronze coinage, and, as discussed in the appendix [1], it also serves as a means of decoupling the axes and avoiding the 'Unit Sum' problem [16].

Figure 5 shows that there is a considerable reduction in the range of compositions seen in the Wang Mang coinage as compared to the Western Han dynasty, which shows a very wide range of compositions. Under Wang

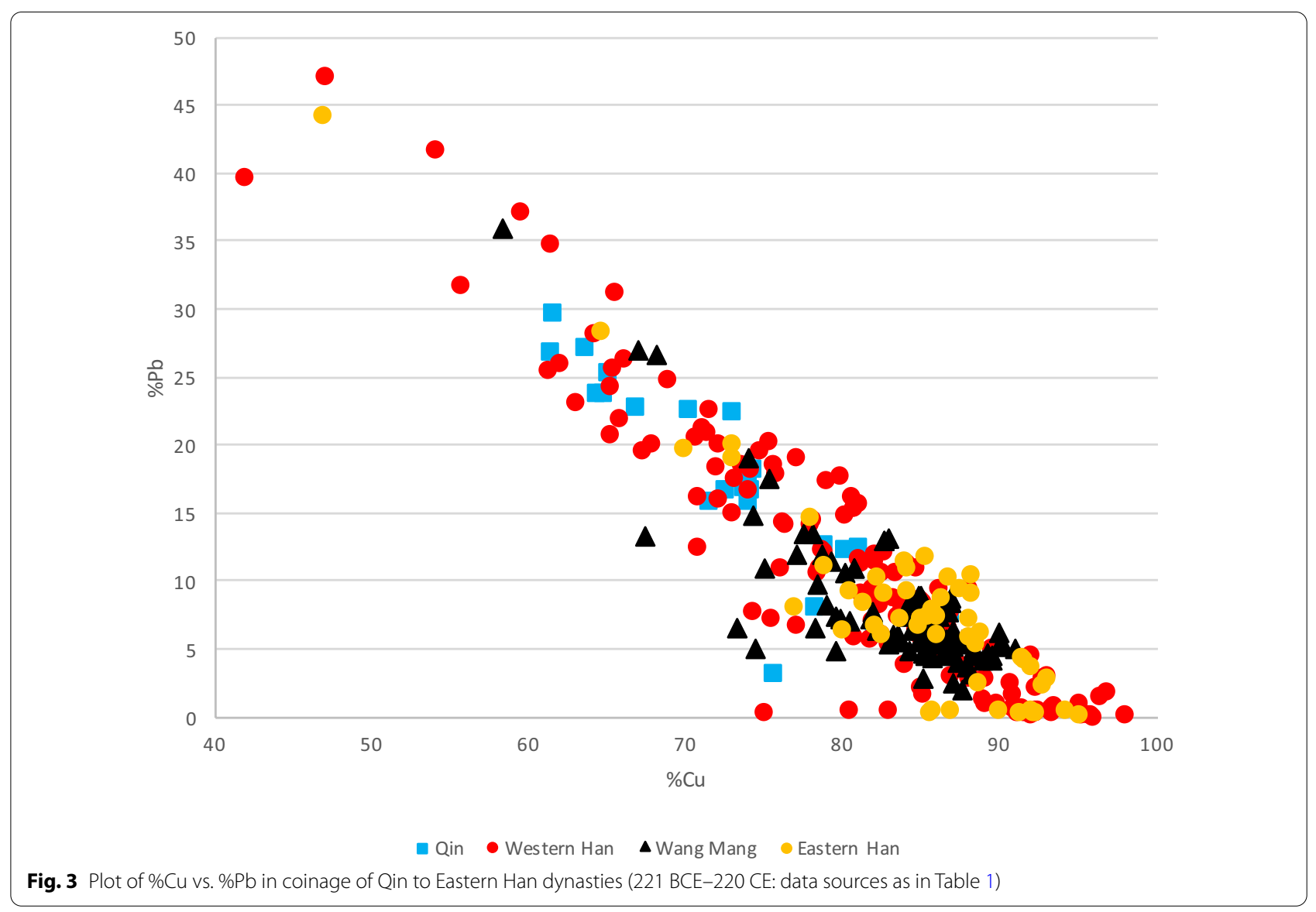




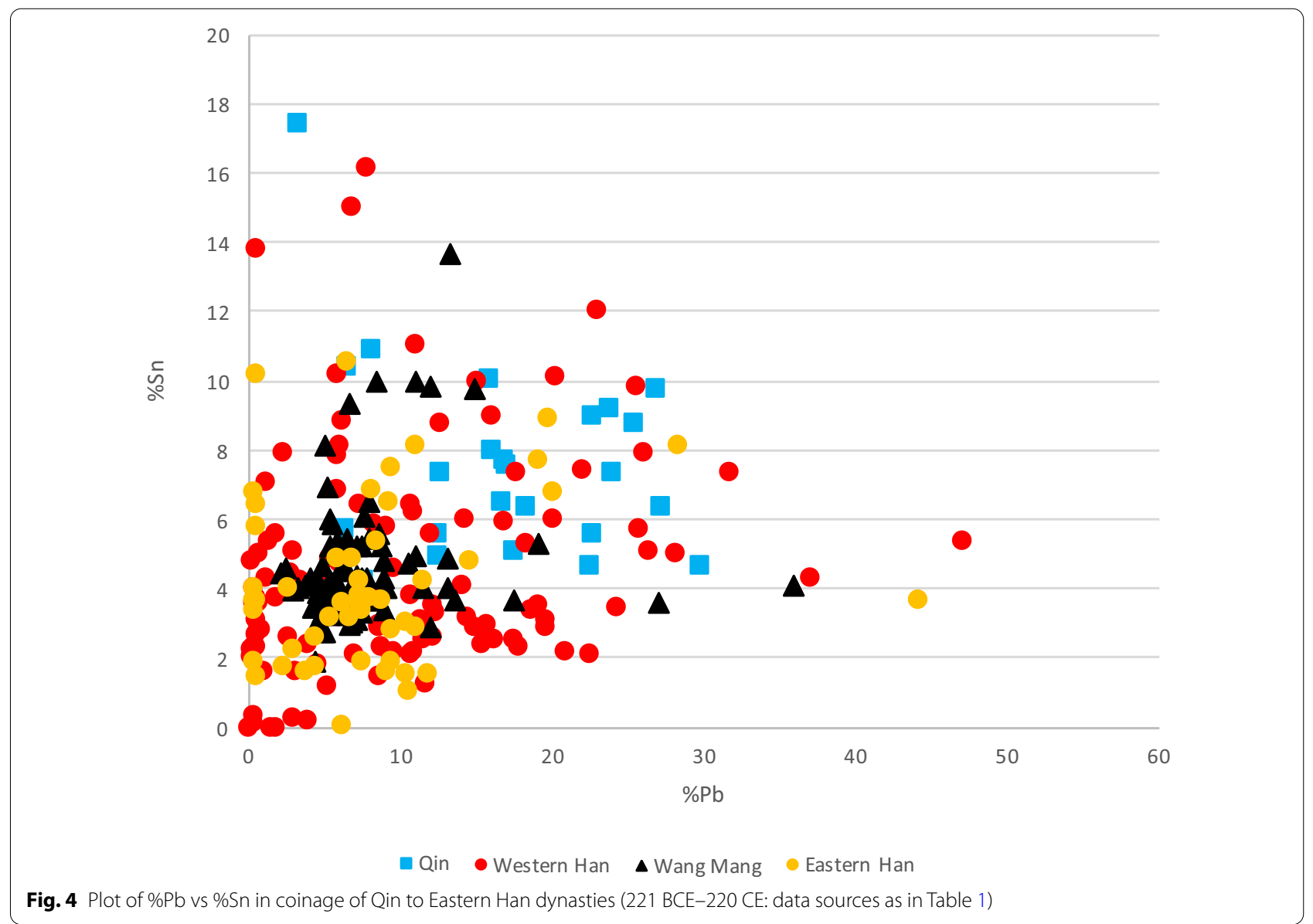

Mang, $\mathrm{Pb} / \mathrm{Cu}$ is confined largely to between 0 and 0.3 , and $\mathrm{Sn} / \mathrm{Cu}$ is similarly reduced to between 0.02 and 0.15 . For orientation, a composition of $\mathrm{Pb} / \mathrm{Cu}=0.1$ and $\mathrm{Sn} /$ $\mathrm{Cu}=0.05$ corresponds to approximately $87 \% \mathrm{Cu}, 4 \% \mathrm{Sn}$ $\%$ and $9 \% \mathrm{~Pb}$. This restriction of compositional variation is probably a consequence of Wang Mang's currency reforms [8], and, from Fig. 5, appears to have been largely preserved when the Eastern Han Dynasty is restored.

There is a further gradual change in the dynasties succeeding the Eastern Han. Figure 6 shows the equivalent plot to Fig. 5 for the Three Kingdoms and Northern and Southern Dynasties, Sui and Tang Dynasties (220 to 907 $\mathrm{CE})$. The $\mathrm{Pb} / \mathrm{Cu}$ ratio is now largely constrained to below 0.6 , but the $\mathrm{Sn} / \mathrm{Cu}$ ratio extends up to 0.3 , rather than being largely below 0.15 in the Han dynasties, indicating that the tin content tends to be higher in this period. The 'target' composition shown in Fig. 6 is the composition calculated from the texts relating to the early Tang (see above), showing a composition of $83 \%$ copper, $15 \%$ lead and $2 \%$ tin, which is substantially lower in tin and lead than in the measured compositions for most of the Tang coinage. By the Tang Dynasty, many of the coins can be assigned to a specific year of issue or to a particular region. Many of the outlying Tang dynasty points in Fig. 6 either come from the year $759 \mathrm{CE}$, and are coinage from the An-Lushan rebellion, or come from Xinjiang province, which was beyond the direct control of the Tang Empire.

Figure 7 shows the same diagram for the coinage of the Five Dynasties and Song period (907-1279 CE). The coinage of the Five Dynasties and Northern Song are similar to the coinage of the preceding Tang Dynasty, but there is a clear shift from the Northern Song to the Southern Song. The latter generally has much higher levels of lead and lower proportions of tin. Figure 8 shows variations between the Liao, Xi Xia, Jin and Yuan Dynasties (907$1368 \mathrm{CE}$ ), showing that Jin, Yuan and some Xi Xia are characterized by higher tin and lower lead, whereas some $\mathrm{Xi}$ Xia and most Liao have very low tin.

\section{The appearance of zinc in the coinage alloy}

For the period considered here (and also the pre-Qin period), Chinese coins can essentially be seen as being made from a ternary copper-tin-lead alloy. The sudden increase in the zinc content of Chinese coinage (up to $20-40 \%)$ from the Jiajing period (1521-1567 CE) of the 


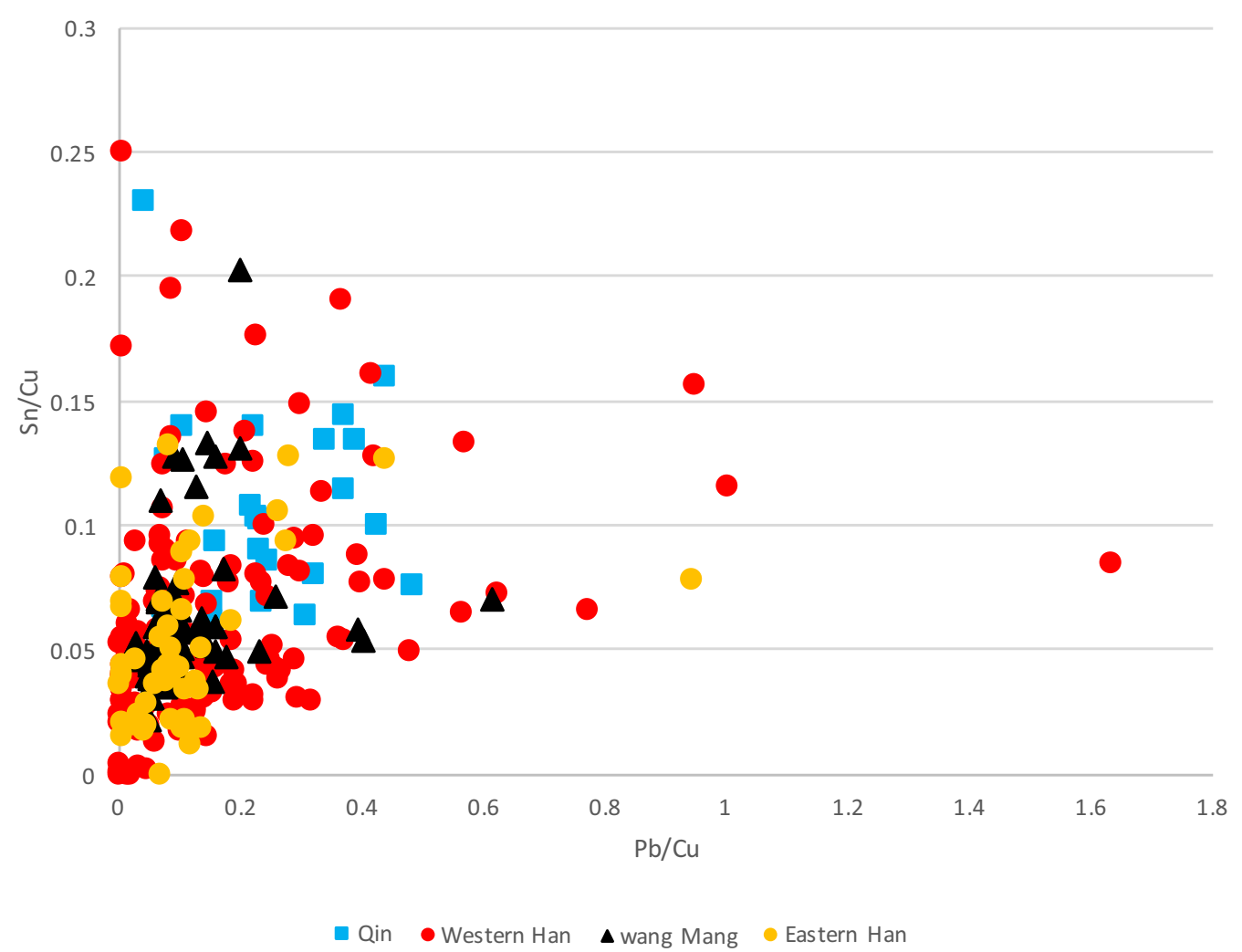

Fig. 5 Plot of Pb/Cu vs Sn/Cu for Qin, Western Han, Wang Mang and Eastern Han (221 BCE-220 CE: data sources as in Table 1)

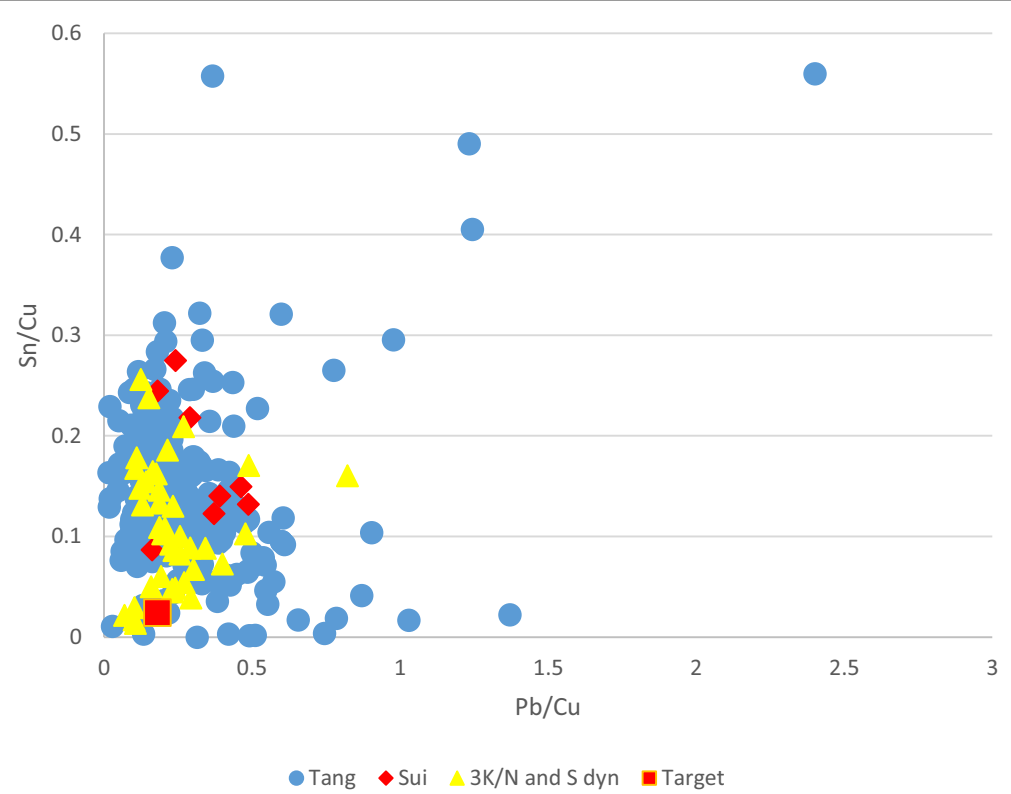

Fig. 6 Plot of Pb/Cu vs Sn/Cu for Three Kingdoms and Northern and Southern Dynasties (220-589 CE), Sui (589-618 CE) and Tang Dynasties (618-907 CE: data sources as in Table 1) 


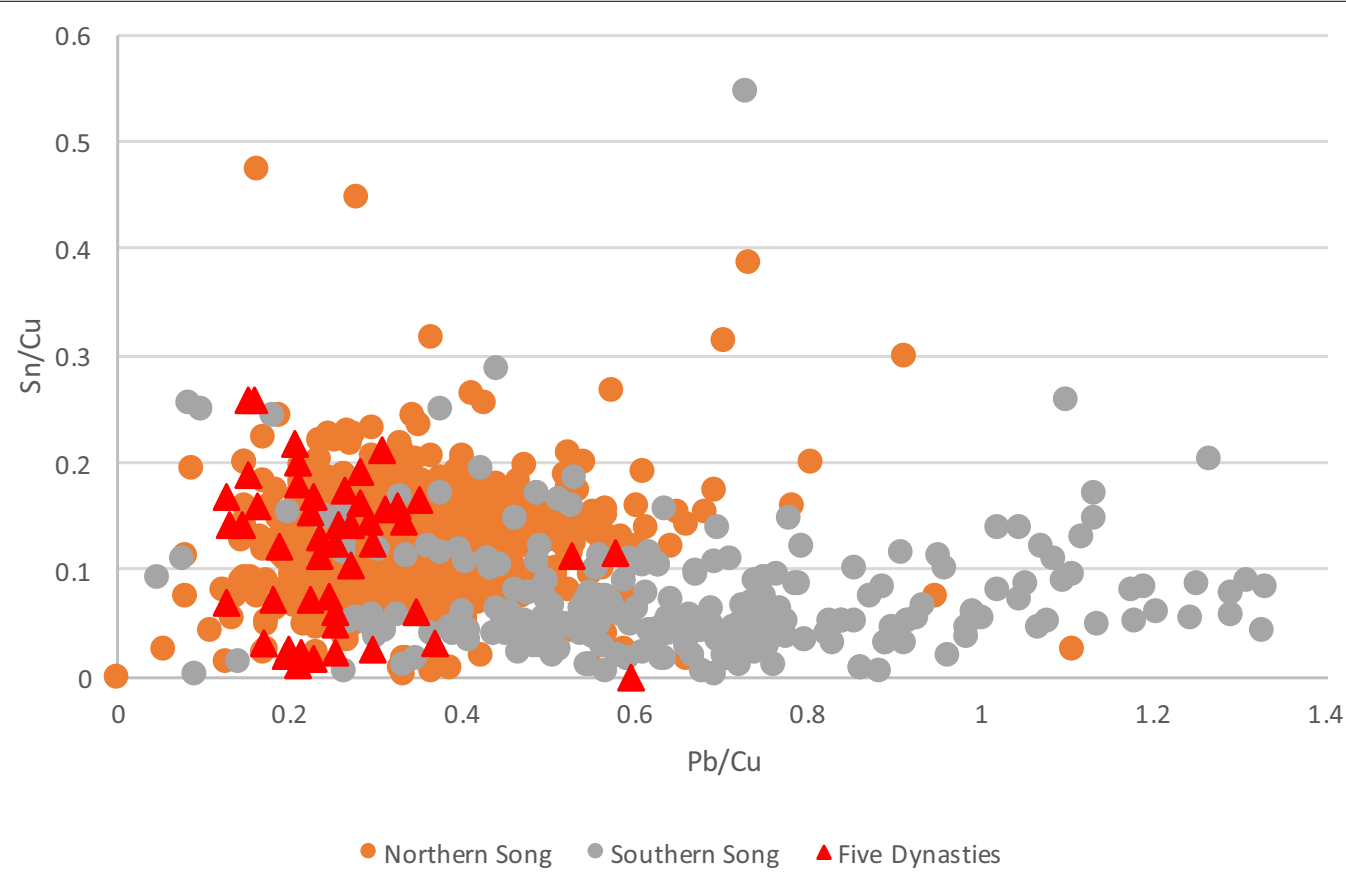

Fig. 7 Plot of Pb/Cu vs Sn/Cu for Five Dynasties (907-960 CE), Northern (960-1127 CE) and Southern Song Dynasties (1127-1279) CE: data sources as in Table 1)

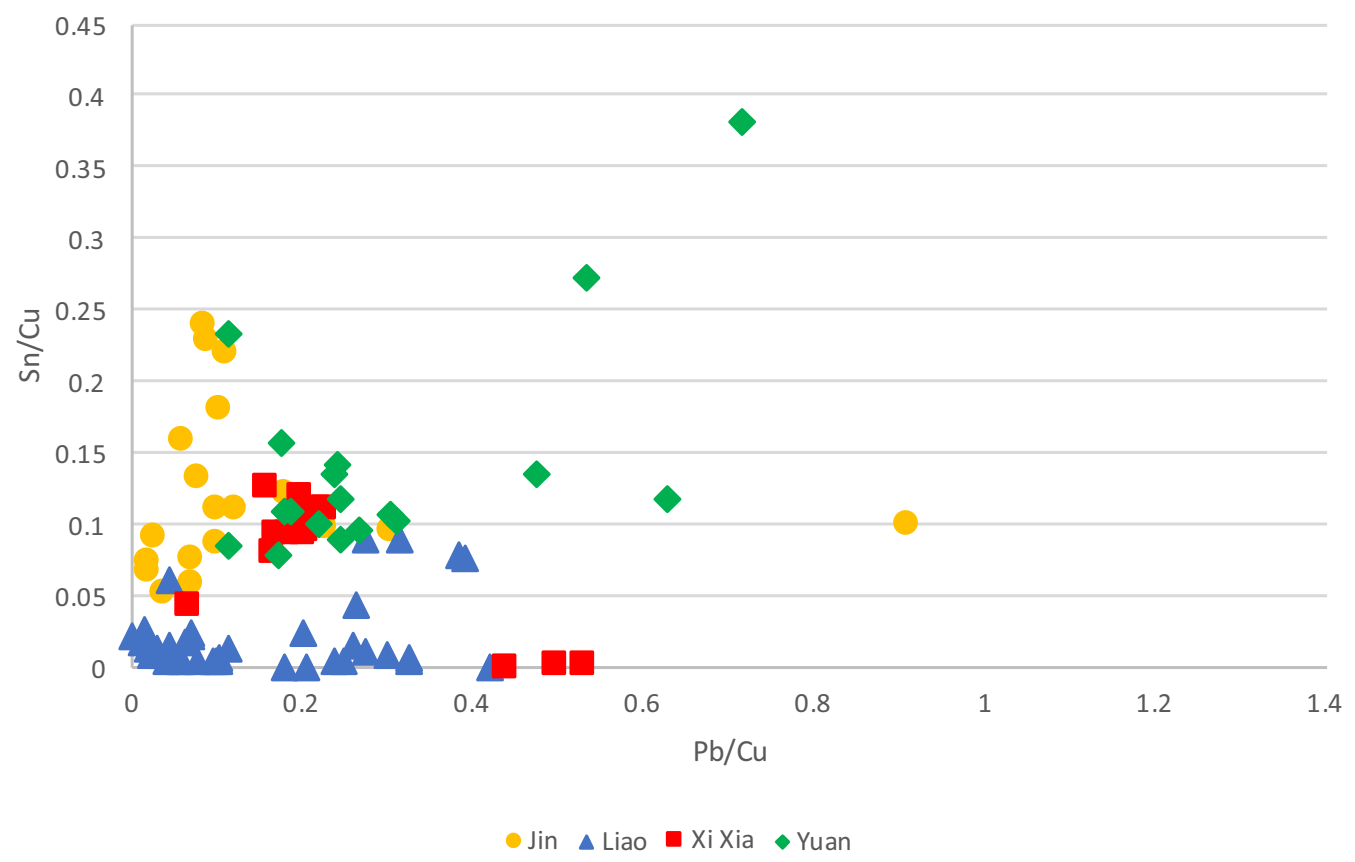

Fig. 8 Plot of Pb/Cu vs Sn/Cu for Liao (907-1125 CE), Xi Xia (1032-1227 CE), Jin 1125-1234) and Yuan Dynasties (1271-1368 CE: data sources as in Table 1)

Ming Dynasty onwards is well-known [2, 17-20] and is not considered further here. Nevertheless, it is clear from the raw data on the composition of Chinese coins from the Qin dynasty onwards that small amounts of zinc were present in some coins. The dataset (including pre Qin) contains 1056 reported values of $\mathrm{Zn}$ in the coinage, the 


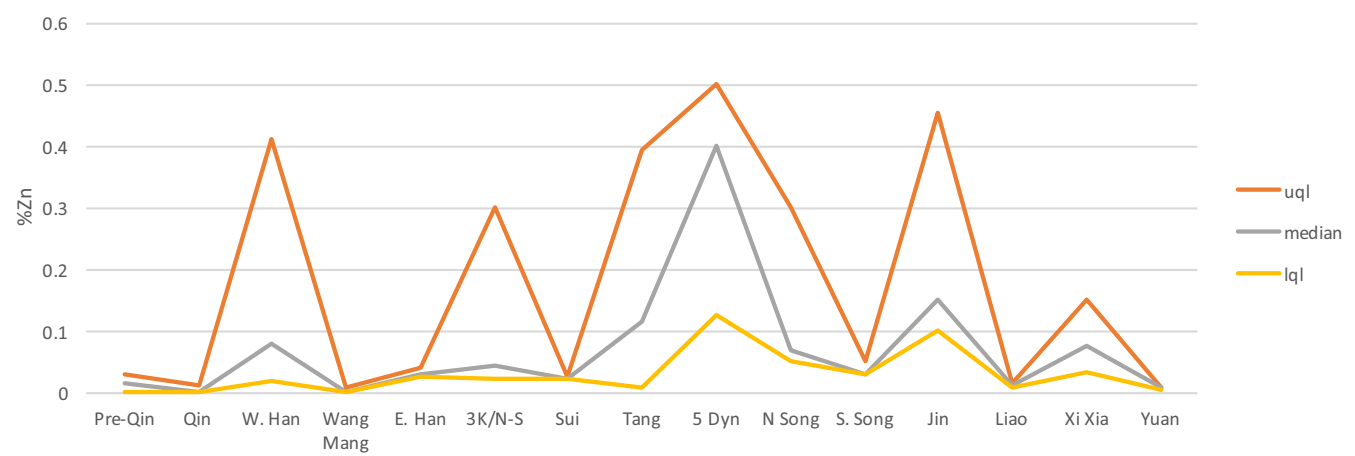

Fig. 9 Levels of zinc (wt \%) present in the coinage of each dynasty, plotted as upper quartile (uql), median (med) and lower quartile (lql) for each period

majority of which $(855$, or $81 \%)$ are $<0.2 \%$ (and are therefore subject to the challenges of comparability discussed above). Figure 9 shows the absolute levels of zinc present (wt \%) in the coinage of each dynasty, plotted as upper quartile (uql), median (med) and lower quartile (lql) for each dynastic period. Although the median levels are generally very low $(<0.1 \%)$, there are higher median values in the Tang (618-907 CE), Five Dynasties/Ten Kingdoms (907-960 CE) and the Jin Dynasty 1125-1234 CE).

Figure 10 shows the maximum level present in the coins of each dynasty. Although obviously such maxima can represent only a single coin, and are therefore susceptible to erroneous analysis, incorrect attribution or the presence of undetected forgeries, nevertheless there is a consistent pattern of values of zinc between 2 and $4 \%$ across a number of dynasties. This might represent accidental incorporation of zinc-containing minerals in the original smelt used to produce the copper or lead, but is higher than would normally be expected under these circumstances. Alternatively, and more interestingly, it might reflect the use of scrap metal containing zinc in the casting melt (i.e., the inclusion of recycled brass). That brass was present in western China (Qinghai province) during the Tang was shown by Li and Han (1992). The manufacture of brass in northern China has been demonstrated in the Jin dynasty (1125- 1234 CE) [21]. Both of these occurrences support the possibility of recycling as an explanation for higher levels of zinc in Chinese coinage.

Brass (in addition to pure copper, but not bronze) was the preferred material to make Buddhist statues, from at least the $9^{\text {th }}$-tenth centuries onwards in Northern India, Tibet and Western China [22]. For example, the analysis of a Gandharan statue of the Buddha from the Victoria and Albert Museum, dated to the fifth century CE, was published by Lo Bue [23] with $68.45 \% \mathrm{Cu}, 20.25 \% \mathrm{Zn}$, $3.86 \% \mathrm{Sn}$ and $3.62 \% \mathrm{~Pb}$. It is therefore worth considering that during the periods of Anti-Buddhist persecution in China, the documented recycling of Buddhist metalwork into coinage could be responsible for slightly higher levels of zinc in some of the coinage. The four major persecutions during this period were:

- 446 CE (Emperor Taiwu of the Northern Wei Dynasty, corresponding to the Three Kingdoms/

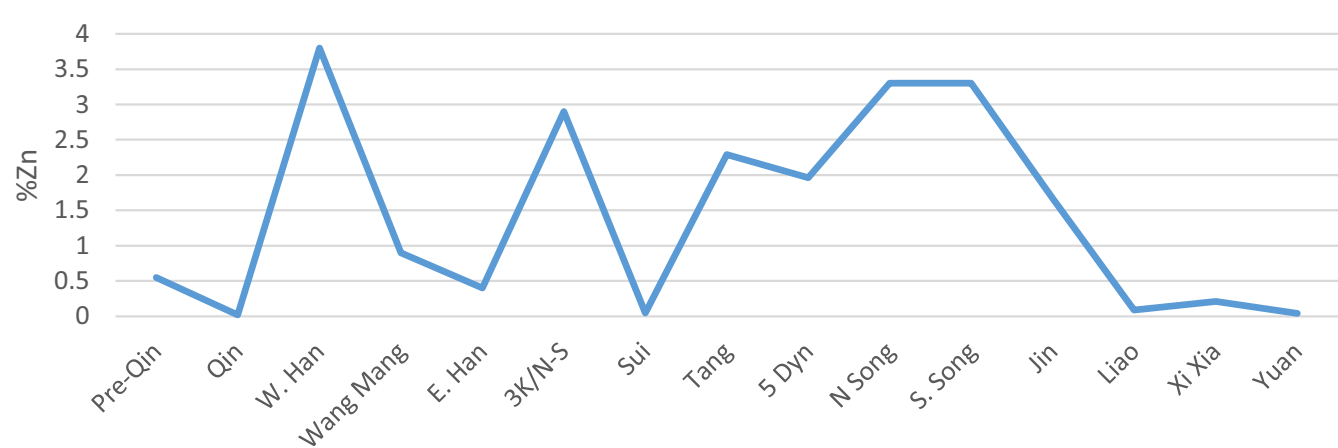

Fig. 10 Maximum levels of zinc (wt \%) present in the coinage of each dynasty 
Northern and Southern Dynasty period in Figs. 9 and 10),

- 574 CE (Emperor Wudi of the Northern Zhou Dynasty-also $3 \mathrm{~K} / \mathrm{N}-\mathrm{S})$,

- 845 CE (Emperor Wuzong of the Tang) and

- 955 CE (Emperor Shizong of the Later Zhou Dynasty, corresponding to the Five Dynasties period in Figs. 9 and 10).

As noted by Reischauer, however, the Tang suppression of $845 \mathrm{CE}$ was by far the greatest of these, covering all of Tang China and permanently crippling Chinese Buddhism, but several other Emperors of all Dynasties carried out repressive measures of great severity [9].

Figure 10 shows that the maximum zinc concentrations are indeed high in the Three Kingdoms/Northern and Southern Dynasties, Tang and Five Dynasties. This is encouraging in the context of the possible recycling of Buddhist metal, but it is also fair to point out that maximum zinc is equally high during the Western Han, Northern and Southern Song dynasties, and the apparent dip in the Sui dynasty is heavily influenced by the paucity of data for that period (only eight recorded analyses). In most cases, the sample size is too small and the chronological resolution too imprecise to determine if the variations in zinc levels reflect the influence of recycled Buddhist metalwork or not, but the current evidence suggests that further investigation is worthwhile. In particular, the rise in zinc traces during the Western Han is extremely interesting, since although this is the date of the earliest contact of China with Buddhism, it is before it became widespread [24].

\section{Variations in silver content across the period}

At its simplest, we suggest that the silver content in a copper alloy object is related to the nature of the added lead, since it is most likely that the silver enters the alloy with the lead rather than the copper in numerous key metal assemblages in early dynastic China [25]. This simple interpretation does not imply, however, that the only source of variation in the silver content in the added lead relates to changes in the geological source of the lead. Different lead deposits can differ naturally in their ratio of $\mathrm{Ag} / \mathrm{Pb}$, but technological processing of the lead, such as cupellation to extract the silver prior to the use of the lead as an alloying component, can affect this ratio. Nevertheless, we suggest that documenting changes in silver content over time can be informative, irrespective of whether these changes are due to changing ore sources, or technological processing, or both. Not all periods have reported silver measurements on the coins, and, as noted above, silver measurements at levels between 0.1 and $0.5 \mathrm{wt} \%$ are likely to be more variable between analytical methods, meaning that the comparability is less secure. Including the pre-Qin coinage addressed in our previous research [1], there are a total of 514 recorded Ag values in the overall dataset. The majority of these measurements (318, or $62 \%$ ) are between 0.001 and $0.1 \mathrm{wt} \%$, and are effectively only semi-quantitative. Figure 11 shows the absolute levels of silver present in coins of each period, although some dynasties have been omitted (particularly the Southern Song) because silver has not been reported. The data are plotted as upper quartile (uql), median (med) and lower quartile (lql) for each period, to guard against individual high (or low) values having an undue influence on the data. The levels of silver are relatively low in most cases, and particularly so in the Eastern Han, Three Kingdoms and the Northern and Southern Dynasties, Tang and Northern Song. This could be due to the exploitation of lead sources that are naturally poor in silver, or it could indicate the desilvering of lead before use as an alloying component. Knowledge of the history of silver production and use in China is not yet comprehensive, but the work of Liu and colleagues [26, 27], has documented domestic silver extraction from at least the Tang Dynasty, and

\section{\%Ag over time}

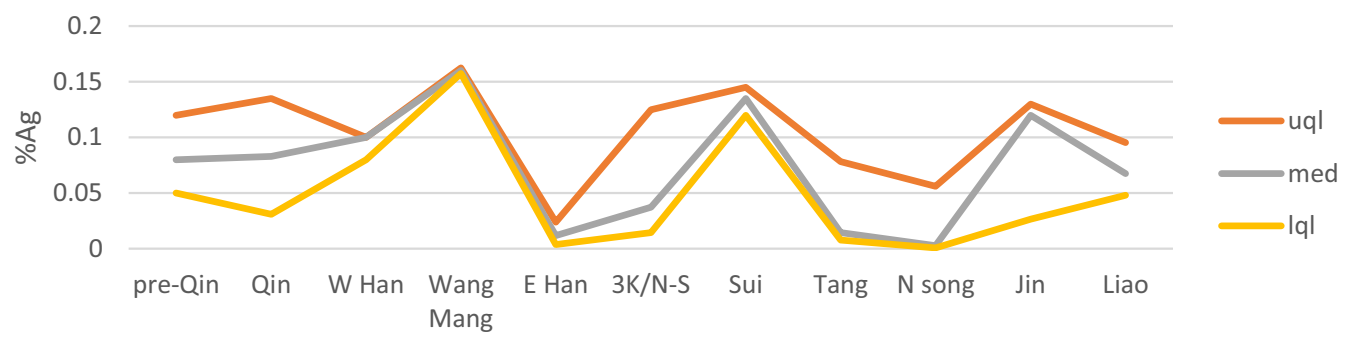

Fig. 11 Levels of silver present in the coinage of each dynasty, plotted as upper quartile (uql), median (med) and lower quartile (lql) for each period 
probably earlier. Figure 11 certainly supports de-silvering from the Tang, but also suggests that de-silvering may have been practiced during the Eastern Han.

\section{Iron as an indicator of copper smelting process}

The level of iron in copper alloys is generally taken to be an indicator of the technology of copper smelting [28]. Based on many modern experimental smelts, the assumption is that the proportion of iron in copper increases as slagging processes are developed, to the point where the raw smelted copper can contain several percent iron. At these levels it becomes necessary for a second (refining) process to remove the excess iron, which would otherwise render the metal unworkable. Craddock and Meeks suggest that iron around $0.05 \mathrm{wt} \%$ indicates copper made by simple non-slagging processes (probably using relatively pure oxide zone minerals), whereas values averaging $0.3 \mathrm{wt} \%$ reflect slagging process, which could involve the use of lower grade oxide zone ores to which iron has been added to remove the silicates, or the use of sulfidic ores.

The dataset (including pre Qin) contains 973 reported values of Fe in the coinage, of which 400 (41\%) are $<0.2 \%$. Figure 12 shows the levels of iron present by dynasty, showing that pre-Qin and Qin coinage have a median below $0.25 \%$, whereas the median in Western Han rises to $0.74 \%$. This figure declines through succeeding dynasties to the Northern Song, but rises dramatically in the Southern Song (median 1.3\%). Although these figures do not correspond precisely with the those given by Craddock and Meeks [28] for the difference between non-slagging and slagging processes, it is plausible to suggest that the increase in iron content in the Western Han coins reflects an increase in copper produced by slagging processes. The gradual decline in median iron values from the Western Han to the Northern Song might suggest that copper refining was increasingly practiced. The quality of the raw copper declined markedly during the Southern Song, at which point the median level of iron jumps to $1.5 \%$.

\section{Conclusions}

This survey of the chemical composition of the copper alloy coinage in China from the Qin Dynasty to the end of the Yuan Dynasty (221 BCE-1368 CE) has attempted to derive broad conclusions about changes in the practice of alloying for coin manufacture over this long period. It is not a numismatic study, and nor can it reflect the detail that is undoubtedly present in the data, due to irregularities in the availability of analyses, and issues associated with comparing chemical data from multiple sources at the minor and trace element levels. What it has shown is a dramatic change in the alloying practice from the period of the Qin unification (after 221 BCE), compared to that used before [1]. From the Qin onwards, the alloying practice seems to follow a more conventional approach, involving independent additions of tin and (predominantly) lead to the base copper. There are a number of changes in the quality of the coinage from dynasty to dynasty reflected in the major element composition. Some of these are well-known, such as the obvious debasement of the Southern Song coinage (1127-1279 $\mathrm{CE})$ when compared to that of the preceding Northern Song dynasty (960-1127 CE), but other areas merit further investigation, such as resolving the data to individual mints where this can be done.

Although we do not see high levels of zinc in the coinage, as seen in the middle Ming dynasty, certain periods do show occasional values of zinc up to $2-4 \%$. This merits further investigation, since the usual explanation of the accidental smelting of mixed $\mathrm{Cu}-\mathrm{Zn}$ ores seems unlikely in such a highly controlled system, and it could reflect the sporadic input of recycled brass $(\mathrm{Cu}-\mathrm{Zn}$ alloy) into the raw material melt. There were four major suppressions of Buddhism during the period considered in this paper-446 CE (Emperor Taiwu of the

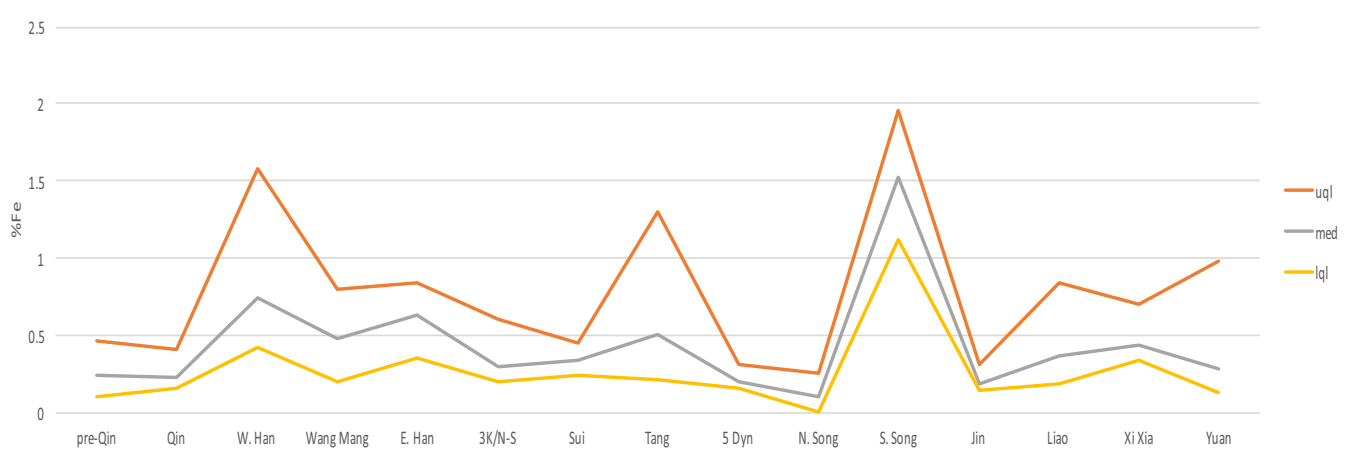

Fig. 12 Levels of iron present in the coinage of each dynasty, plotted as upper quartile (uql), median (med) and lower quartile (lql) for each period 
Northern Wei), 567 CE (Emperor Wudi of the Northern Zhou), 845 CE (Emperor Wuzong of the Tang) and 955 CE (Emperor Shizong of the Later Zhou). These suppressions are recorded as times when Buddhist statuary (some of which would have been brass) was recycled into the coinage, providing a plausible mechanism for the injection of small quantities of zinc into the coinage alloy. The currently available data provides weak support for this suggestion, but more data are required.

A similar diachronic study of the amounts of iron in the metal, taken to indicate changes to the manufacturing process of copper, show some changes over time. The median levels of iron jump from below $0.25 \%$ in the Qin (221-206 BCE) to $0.74 \%$ in the Western Han (206 BCE-9 CE), possibly reflecting the adoption of slagging processes in the production of copper during the Western Han. The rapid increase in iron during the Southern Song (1127-1279 CE) undoubtedly reflects a crisis in the supply of copper during this period. Finally, a study of the content of silver also reveal changes over time, possibly associated with differences in the sources of lead, or changes in lead and silver extraction technologies, over the period.

The overview provided here is, of necessity, a preliminary statement on what can be achieved by a systematic study of the changes in metal supply and alloying practice using coinage data. It is constrained by the lack of good quality compositional data for the coinage for some periods, and more data will undoubtedly reveal more important detail-particularly for the periods from the Tang Dynasty onwards, where some coins can be assigned to specific years of production. In particular, the suggestion that the low levels of zinc in some of the coinage of the first millennium $\mathrm{CE}$ reflect the use of recycled brass in the process. Given the literary references to the use of recycled Buddhist metalwork (some of which would be brass) at times of suppression, it would be worthwhile to concentrate on some relevant coinage issues through this period to illuminate this point further. The intention of this paper is to stimulate further work, both analytically and synthetically.

\section{Acknowledgements}

We are grateful for the comments of four anonymous reviewers on a previous version of this paper. It would not, of course, have been possible without the dedicated work of many researchers who have carried out the chemical analysis of Chinese coins.

\section{Authors' contributions}

AMP plot data analysis, RL contributed to data interpretation, both wrote the paper together. Both authors read and approved the final manuscript.

\section{Funding}

No specific source of external funding was used to support this research It was enabled by the support of the School of Archaeology, University of Oxford.

\section{Availability of data and materials}

See online supplementary material and http://flame.arch.ox.ac.uk/publicresources.

\section{Declarations}

Competing interests

The authors declare that they have no competing interests.

\section{Author details}

${ }^{1}$ Asia Department, British Museum, London WC1E 7JW, UK. ${ }^{2}$ Research Laboratory for Archaeology and the History of Art, School of Archaeology, University of Oxford, Oxford, England.

Received: 17 February 2021 Accepted: 7 May 2021

Published online: 22 May 2021

\section{References}

1. Pollard AM, Liu R. Bronze alloying practice in ancient china-evidence from pre-qin coin analyses. J Arch Sci. 2021. https://doi.org/10.1016/j.jas. 2020.105322.

2. Dai Z, Zhou W. Studies of the alloy composition of more than two thousand years of chinese coins (5th century bc-20th century ad). J Hist Met Soc. 1992;26:45-55.

3. Sun L, Yang G, Liu R, Pollard AM, Zhu T, Liu C. Global circulation of silver between Ming-Qing China and the Americas: Combining historical texts and scientific analyses. Archaeometry. 2021. https://doi.org/10.1111/ arcm.12617.

4. Wang H. A short history of Chinese numismatics in European languages. Ea China. 2013;35:395-429.

5. Wang H, Cowell M, Cribb J, Bowman S. Metallurgical analysis of Chinese coins at the British Museum. London: British Museum; 2005.

6. Zhou W, Dai Z. Papers on numismatics and the history of metallurgy. Beijing : Zhonghua Shuju; 2002. (in Chinese).

7. Zhou W. Chinese coin alloying composiiton and metallurgical reserch. Beijing : Zhonghua Shuju; 2004. (in Chinese).

8. Hartill D. Cast chinese coins. A historical catalogue. Victoria BC: Trafford Publishing; 2005.

9. Reischauer EO. Ennin's travels in tang china. New York: Ronald Press; 1955.

10. Ma T, Xing Q, Li M, et al. Discussion of the budda-destroy coins in Chinese coin history. Orient Arch. 2018;15:78-91 (in Chinese).

11. Bowman S, Cowell MR, Cribb J. Two thousand years of coinage in china: an analytical survey. J Hist Met Soc. 1989;23:25-30.

12. Cowell MR, Cribb J, Bowman S, Shashoua Y. The Chinese cash: composition and production. In: Archibald MM, Cowell MR, editors. Metallurgy and numismatics. London: Royal Numismatic Society Special Publication; 1993. p. 185-98.

13. Cowell MR, Wang H. Metal supply for the metropolitan coinage of the kangxi period (1662-1721). Numismatic Chron. 1998;158:185-96.

14. Pollard AM, Bray P, Hommel P, Liu R, Pouncett J, Saunders M, et al. Beyond provenance : New approaches to interpreting the chemistry of archaeological copper alloys. Belgium: Leuven University Press; 2018.

15. Caley ER. The composition of ancient greek bronze coins. Philadelphia: American Philosophical Society, Memoirs; 1939.

16. Aitchison J. The statistical analysis of compositional data. Caldwell: Blackburn Press; 1986.

17. Zhou W. A new study of the history of zinc in china. Stud Hist Nat Sci. 1991;10:259-66 (in Chinese).

18. Zhao K, Chen R, Zhou W, Guo Y, Cheng Y, Hua J, et al. A study of the alloy composition of the warring states coins. Stud Hist Nat Sci. 1992;11:32-44 (in Chinese).

19. Zhou W, Fan X. A study on the development of brass for coinage in China. Bull Met Mus. 1993;20:16-21.

20. Cowell MR, Wang H. Metal supply for the metropolitan coinage of the Kangxi period. Numismatic Chron. 1998;158:185-96.

21. Xiao H, Huang X, Cui J. Local cementation brass production during 12-13th century ce, north China: Evidences from a royal summer palace of Jin dynasty. J Arch Sci: Rep. 2020;34:1-8. 
22. Pollard AM, Liu R, Howarth P. From alexander the great to the buddha: Buddhism and the introduction of brass technology into china. Arch Research Asia (under review)

23. Lo BE. Statuary metals in tibet and the himalayas: history, tradition and modern use. Bulletin of Tibetology. 1991;27:7-41.

24. Rhie MM. Early buddhist art of China and Central Asia. In: Later Han, Three Kingdoms and Western Chin in China and Bactria to Shan-Shan in Central Asia, Vol 1. Leiden: Brill; 1999. https://doi.org/10.1163/9789047430759

25. Liu R, Pollard AM, Liu C, Rawson J. Every cloud has a silver lining: Using silver concentration to identify the number of sources of lead used in Shang dynasty bronzes. Acta Geol Sin . 2020;94:585-93.

26. Liu S. Gold and silver production in imperial China: technological choices in their social-economic and environmental settings. Unpublished PhD dissertation thesis. University College London, 2015
27. Liu S, Rehren T, Chen JL, Xu CQ, Venunan P, Larreina-Garcia D. Bullion production in imperial China and its significance for sulphide ore smelting world-wide. J Arch Sci. 2015;55:151-65.

28. Craddock PT, Meeks ND. Iron in ancient copper. Archaeometry. 1987;29:187-204.

\section{Publisher's Note}

Springer Nature remains neutral with regard to jurisdictional claims in published maps and institutional affiliations.

\section{Submit your manuscript to a SpringerOpen ${ }^{\circ}$ journal and benefit from:}

- Convenient online submission

- Rigorous peer review

- Open access: articles freely available online

- High visibility within the field

- Retaining the copyright to your article

Submit your next manuscript at $\boldsymbol{\nabla}$ springeropen.com 